\title{
Implementasi Metode Reverse Osmosis Pada Perhitungan Kapasitas Tangki Pengolahan Air Laut
}

\author{
Nuryasin Abdillah \\ Program Studi Teknik Sipil, Sekolah Tinggi Teknologi Dumai \\ Jl. Utama Karya Bukit Batrem II \\ e-mail: yasinabdillah10@gmail.com
}

\begin{abstract}
ABSTRAK
Air terbagi beberapa jenis seperti asin dan air tawar. Air asin terdapat di laut karena memiliki memiliki rasa asin berlebih. Pada musim kemarau panjang masyarakat kesulitan mendapatkan air bersih. Masyarakat memerlukan tangki penyedia air untuk menampung dan mengolah air bersih dengan menggunakan membran. Membran pengolah air umumnya berbasiskan polimer. Tangki penyedia air dihitung kapasitasnya baik dari bahan plat stainless steel, viber dan beton untuk menentukan ukuran dengan menghitung menggunakan kecepatan aliran baik itu bentuk tabung maupun berbentuk balok. Dalam pelaksanaan penelitian ini pada saat teknik pengolahan didapatkan dari data sekunder oleh pihak perusahaan agar pengolahan air dari zat terlarut yang tinggi menjadi rendah sedangkan perhitungan kapasitas tangki dihitung dengan metode Mc. Cabe and Smith dan dibandingkan dengan data primer perusahaan agar metode perhitungan ini dapat dipakai pada saat merancang tangki untuk pengolahan air laut dengan menggunakan mesin reverse osmosis
\end{abstract}

Kata Kunci:, Air Laut, Membran, Reverse Osmosis, Tangki

\begin{abstract}
Water is divided into several types such as salty and fresh water. Salt water is found in the sea because it has an excessive salty taste. During the long dry season, people have difficulty getting clean water. Communities need water supply tanks to accommodate and treat clean water using membranes. Water treatment membranes are generally polymer based. The capacity of the water supply tank is calculated from stainless steel plate material, viber and concrete to determine the size by calculating using the flow velocity, either in the form of a tube or in the form of a beam. In the implementation of this research when processing techniques obtained from secondary data by the company so that water treatment from high dissolved substances becomes low, while the calculation of tank capacity is calculated by the Mc. Cabe and Smith and compared with the company's primary data so that this calculation method can be used when designing tanks for seawater treatment using a reverse osmosis machine.
\end{abstract}

Keywords: Sea water, Membrane, Reverse Osmosis, Tank 


\section{Pendahuluan}

Air adalah senyawa penting bagi semua bentuk kehidupan di bumi. Air menutupi $3 / 4$ permukaan bumi. Manusia sering dihadapkan pada situasi yang sulit dimana sumber air tawar sangat terbatas dan di lain pihak terjadi peningkatan kebutuhan (Akhsan, 2011). Bagi masyarakat air tawar merupakan sumber air yang sangat penting. Sering terdengar ketika musim kemarau mulai datang maka masyarakat yang tinggal di daerah pantai atau pulau kecil-kecil mulai kekurangan air. Air hujan yang merupakan sumber air yang telah disiapkan di bak penampung air hujan (PAH) sering tidak dapat mencukupi kebutuhan pada musim kemarau (Arieyanto, 2014).

Padahal kita mengetahui bahwa sebenarnya sumber air asin itu begitu melimpah, kenyataan menunjukkan bahwa ada banyak daerah pemukiman yang justru berkembang pada daerah pantai. Melihat kenyataan semacam itu manusia telah berupaya untuk mengolah air asin/payau menjadi air tawar mulai dari yang menggunakan teknologi sederhana seperti menyuling, filtrasi dan ionisasi (pertukaran ion) (Rezagama, 2009). Sumber laut yang jumlahnya sangat melimpah telah membuat manusia berfikir untuk mengolahnya menjadi air tawar (Ihsanudin, 2017).

Untuk memenuhi kebutuhan akan air tawar manusia telah mengembangkan sistem pengolahan air asin/payau dengan teknologi membran semipermeabel. Membran (selaput) semipermeabel adalah suatu selaput penyaring skala molekul yang dapat ditembus oleh molekul air dengan mudah, akan tetapi tidak dapat atau sulit sekali dilalui oleh molekul lain yang lebih besar dari molekul air (Nurtendron, 2018).

Teknologi pengolahan air asin/payau yang akan dibahas pada tulisan ini terutama yang menggunakan teknologi filtrasi membran semipermeabel. Teknologi pengolahan air asin/payau ini lebih dikenal dengan sistem (Reverse Osmosis disingkat RO). Teknologi ini menerapkan sistem osmosis yang dibalik yaitu dengan memberikan tekanan yang lebih besar dari tekanan osmosis air asin/payau. Air asin/payau tersebut ditekan supaya melewati membran yang bersifat semi permeabel, molekul yang mempunyai diameter lebih besar dari air akan tersaring

\section{Metode Penelitian}

Penelitian yang dilakukan adalah analisa perhitungan tangki air pada proses air asin ke air tawar reverse osmosis. Tahap perencanaan yang dilakukan diantaranya : Studi Literatur, Pengumpulan Data, Analisis, Perencanaan proyeksi pengunjung dan kebutuhan air dan analisis data kelayakan teknis dan ekonomis. Dalam proses penelitian diperlukan data yang komplek dan diperlukan informasi data yang valid dan adanya diperlukan dalam menggunakan beberapa alat penunjang untuk sebagai bahan penelitian. Data yang berasal dari hasil pengamatan dilokasi penelitian dan data sekunder dari instansi terkait dianalisis (Wiranata,2014). Dalam pengolahan air laut menggunakan alat reverse osmosis yaitu alat yang akan digunakan untuk menyaring adalah mesin SWRO (Sea Water Reverse Osmosis) dan BWRO (Brackish Water Reverse Osmosis. Untuk perhitungan tangki adalah dengan menggunakan rumus metode Mc. Cabe and Smith. 
Unitek : Jurnal Universal Teknologi

Vol. 14 No.1 Januari-Juni 2021

e-ISSN : 2580-2582, p-ISSN: 2089-3957

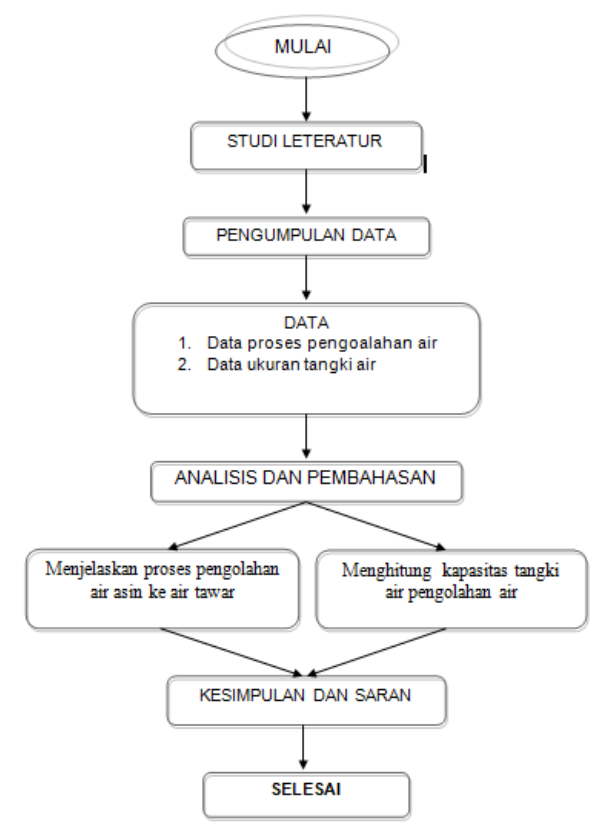

Gambar 1. Diagram Alur Penelitian

\section{Hasil dan Pembahasan}

Data yang diperoleh atau persyaratan yang harus digunakan dengan catatan

Flow rate (laju aliran)

$$
\begin{aligned}
& =\geq 110 \mathrm{~m}^{3} / \mathrm{h} \\
& =4,2 \mathrm{bar} \\
& =<16000 \mathrm{ppm}
\end{aligned}
$$

TDS (Totaly Dissolve Solid/jumlah zat terlarut)

Backwashing atau tanki backwasing biasanya digunakan jika tekanan air masuk dan keluar kurang dari 1 bar karena tidak terjadi perubahan pada teknanan air ini.

Tabel 1. Data MMF

\begin{tabular}{lll}
\hline Multimedia Filter & \multicolumn{1}{c}{$\begin{array}{c}\text { Inlet Water } \\
\text { Quality }\end{array}$} & \multicolumn{1}{c}{$\begin{array}{c}\text { Outlet Water } \\
\text { Quality }\end{array}$} \\
\hline Jumlah & $3 \quad$ tangki & \\
Flow rate / unit & $50 \mathrm{~m}^{3} / \mathrm{h}$ & $50 \quad{ }^{3} / \mathrm{h}$ \\
Turbidity & $<20 \mathrm{NTU}$ & $<5 \mathrm{NTU}$ \\
$T D S$ & $<36000 \mathrm{ppm}$ & $<36000 \mathrm{ppm}$ \\
Ph & $<8,5$ & $<8,5$ \\
$\mathrm{Hardness}$ & & \\
$\mathrm{Ca}$ & $<245 \mathrm{ppm}$ & $<245 \mathrm{ppm}$ \\
$\mathrm{Mg}$ & $<350 \mathrm{ppm}$ & $<350 \mathrm{ppm}$ \\
$\mathrm{Fe}$ & $<0,2 \mathrm{ppm}$ & $<0,2 \mathrm{ppm}$ \\
\hline
\end{tabular}

Pressure 2 bar, jika pengeluaran kembali tidak dapat memulihkan UF ke kondisi normal sehingga digunakan $\mathrm{NaOCl}$ dengan langkah-langkah berikut:

Langkah 1 : mengatur ulang dengan pada 200 ppm NaOCl 10-30 mnt

Langkah 2 : Rendam Statik dengan $\mathrm{NaOCl} 200$ ppm (optimal)

Langkah 3 : Bersihkan asam sitrat atau nitrat (PH2-3) selama 10-30 menit

Langkah 4 : Siram dengan tiriskan air mentah selama 30 detik. 
Perhitungan kapasitas tangki berfungsi untuk menyediakan bahan-bahan penunjang yang mendukung kelancaran pada sistem produksi di pabrik. Unit-unit yang ada di utilitas terdiri dari :

1) Unit penyediaan dan pengolahan air (Water System)

2) Unit pembangkit steam (Steam Generation System)

3) Unit penyedia udara instrument (Instrument Air System)

4) Unit pembangkit dan pendistribusian listrik (Power Plant and Power Distribution System)

Sand filter yang digunakan berfungsi untuk menyaring kotoran yang masih terdapat dalam air dengan tipe vertikal silinder tegak dengan tutup atas dan bawah torispherical dan dengan media penyaring pasir

Kondisi operasi : $\quad$ Tekanan MMF $\quad=4,2$ bar

$$
\begin{array}{ll}
\text { Tekanan } & =5 \mathrm{bar} \\
\text { Q(MMF) } & =. \geq 110 \mathrm{~m} 3 / \mathrm{jam} \\
\text { Q(DMF) } & =. \geq 85 \mathrm{~m} 3 / \mathrm{jam} \\
\text { Temperatur } & =30^{\circ} \mathrm{C}
\end{array}
$$

\section{1) Multi Media Filter}

a. Menentukan luas dan dimensi filter

Kapasitas tangki $=$ total air masuk filter

$$
\begin{aligned}
& =50 \mathrm{~m}^{3} / \mathrm{jam} \times\left(1,03 \times 10^{3}\right) \mathrm{kg} / \mathrm{m}^{3} \\
& =51.500 \mathrm{~kg} / \mathrm{jam} \\
& =50 \mathrm{~m}^{3} / \mathrm{jam} \times(264,172 / 60) \text { galon } / \text { menit } \\
& =220,1433 \mathrm{gpm}
\end{aligned}
$$

Laju filtrasi $=2-4 \mathrm{gpm} / \mathrm{ft}^{2}$

Dipilih $=4 \mathrm{gpm} / \mathrm{ft}^{2}$

Luas penampang $A=\frac{220,1413 \mathrm{gpm}}{4 \mathrm{gpm} / \mathrm{ft}^{2}} \quad=55,035825 \mathrm{ft}^{2}$

Diameter tangki : $A=\frac{4}{4} X D^{2}$

$$
\begin{aligned}
D= & {\left[\frac{4 x A}{\pi}\right]^{1 / 2} } \\
& =\sqrt{\frac{\left[4 \times 55,0035825 \mathrm{ft}^{2}\right]}{2,14}}=8.373131493055629 \mathrm{ft} \\
& =8.373131493055629 \mathrm{ft} \times 0,3048
\end{aligned}
$$

Jari jari $\mathrm{R} \quad \mathrm{D}_{\text {atandar }}=1 / 2 \mathrm{D}$

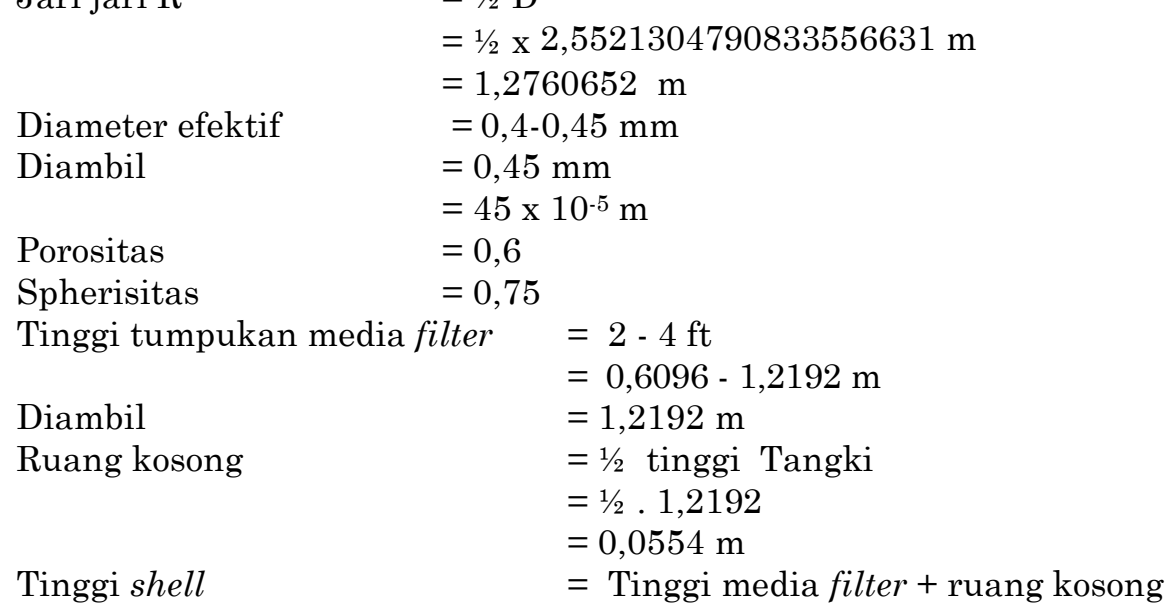


b. Menghitung Tebal dinding

$$
=1,2192 \mathrm{~m}+0,0554 \mathrm{~m}=1,274609 \mathrm{~m}
$$

Tekanan desain :

Poperasi $=4,2 \times 14,5038=60,9158$ psi

Menghitung tekanan vertikal bahan padat pada dasar tangki digunakan persamaan Jansen :

PB

$$
=\frac{R \rho B(\text { g }}{2 \mu N)}\left[1-e^{-2 \mu K Z T / R}\right]
$$

Diperoleh $\rho B$

$$
\begin{aligned}
& =106,0338 \mathrm{lb} / \mathrm{ft}^{3} \\
& =0,7363 \mathrm{lb} / \mathrm{in} 2
\end{aligned}
$$

Tekanan lateral yg dialami dinding tangki

PL

$$
\begin{aligned}
& =\mathrm{K} \cdot \mathrm{PB} \\
& =0,5 \mathrm{x} \quad 0,7363 \mathrm{lb} / \mathrm{in} 2 \\
& =0,36815 \mathrm{lb} / \mathrm{in}^{2}
\end{aligned}
$$

Tekanan total (PT)

$\mathrm{P}$ total $=60,9158+0,7363+0,36815=62,02025 \mathrm{lb} / \mathrm{in}^{2}$

Tekanan desain $5-10 \%$ di atas tekanan kerja normal/absolut Tekanan desain yang dipilih 10\% diatasnya.

Pdesain $=1,1 \times 62,02025=68,2222275 \mathrm{psi}$

Tebal shell, $\mathrm{t} s=\frac{F F \pm}{f E-0.6 P}+C$

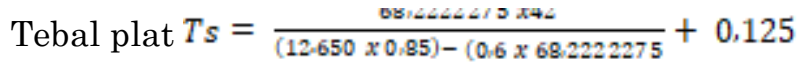

$$
=0,39249902=0,4 \text { in }
$$

Diperoleh ts $=2 / 5$ in atau $1 / 2$ in $(2 \mathrm{~cm})$ dan diambil ts standar $1,016 \mathrm{~cm}$

c. Menentukan Head dan Bottom

$$
\begin{array}{ll}
\mathrm{w} & =\frac{1}{4}\left(3+\sqrt{\frac{\text { rev }}{\text { ier }}}\right) \\
\mathrm{OD} & =\mathrm{ID}+2 \cdot \mathrm{t}_{\mathrm{S}} \\
& =42+2 \cdot(0,393701) \\
& =42,787402 \mathrm{in}
\end{array}
$$

untuk OD 42 in dan ts 0,1875 in diperoleh :

rc

$=48$ in

icr

$=3$ in

$\mathrm{w}$

$$
\begin{aligned}
& =\frac{1}{4}\left(3+\sqrt{\frac{r e}{i c r}}\right) \\
& =\frac{1}{4}\left(3+\sqrt{\frac{48}{a}}\right)=1,7500 \mathrm{in}
\end{aligned}
$$

Menentukan tebal head dengan menggunakan persamaan

$$
\begin{aligned}
& \text { th } \quad=\frac{P r c W}{2 f E-0,2 P}+C
\end{aligned}
$$

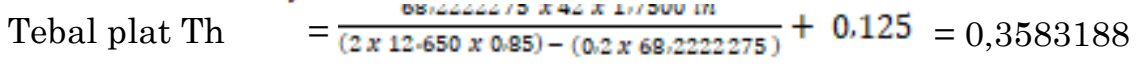

$$
\begin{aligned}
& =0,4 \text { in } \\
& \text { Untuk th }=1 / 2 \text { in, } \quad \text { sf }=1,5-2,25 \text { in }
\end{aligned}
$$

d. Menentukan tinggi head, OA

$$
\begin{aligned}
& b \quad=r c-\sqrt{(r c-i c r)^{2}-\left(\frac{I D}{2}-i c r\right)} \\
& =25,5501 \mathrm{in} \\
& =0,4+25,5501+2
\end{aligned}
$$


Unitek : Jurnal Universal Teknologi

Vol. 14 No.1 Januari-Juni 2021

e-ISSN : 2580-2582, p-ISSN: 2089-3957

$$
\begin{aligned}
& =27,8001 \mathrm{in} \\
& =0,7099 \mathrm{~m}
\end{aligned}
$$

e. Menghitung volume total filter

Volume tanpa bagian sf :

$\mathrm{V}=0,000049 \mathrm{D}^{3}$

$$
=0,000049(2,552)^{3} \quad=0,0008144 \mathrm{~m}^{3}
$$

Volume pada sf :

$$
\begin{aligned}
& \text { Vsf }=\frac{\pi \times D^{2} \times s f}{4} \\
& \text { Vsf }=\frac{3.14 \times^{4} \cdot 552^{2} \times 2}{4} \quad=10,2249453 \mathrm{~m}^{3} \\
& V_{\text {head }} \quad=0,0008144 \mathrm{~m}^{3}+10,2249453 \mathrm{~m}^{3}=10,2258 \mathrm{~m}^{3}
\end{aligned}
$$

\begin{tabular}{|c|c|}
\hline $\begin{array}{l}\text { Internal back washing } \\
\text { Debit Aliran Backwashing }\end{array}$ & $\begin{array}{l}=12 \mathrm{jam} \\
=50 \mathrm{~m}^{3} / \mathrm{jam}\end{array}$ \\
\hline $\begin{array}{l}\text { Kecepatan backwash } \\
\mathrm{A} \quad=25,29 \mathrm{~m}^{2}\end{array}$ & $\begin{array}{l}=15 \mathrm{gpm} / \mathrm{ft}^{2} \quad\left(15-30 \mathrm{gpm} / \mathrm{ft}^{2}\right) \\
=272,219294 \mathrm{ft}^{2}\end{array}$ \\
\hline Kecepatan backwash & $\begin{array}{l}=15 \mathrm{gpm} / \mathrm{ft}^{2} \times 272,219294 \mathrm{ft}^{2} \\
=4083,2894 \mathrm{gpm}\end{array}$ \\
\hline Air untuk backwash & $\begin{array}{l}=0,5-5 \% \\
=4 \% \text { air yang disaring }\end{array}$ \\
\hline Air untuk backwash & $\begin{array}{l}=4 \% \times 50 \mathrm{~m}^{3} / \mathrm{jam} \times 12 \mathrm{jam} \\
=24 \mathrm{~m}^{3} \\
=6340,13 \text { gallon } \\
6.340,12 \text { gallon }\end{array}$ \\
\hline Waktu backwash & $\begin{array}{l}=\overline{4003 a_{2} 2894 \mathrm{gpm}} \\
=1,55527016 \text { menit } \\
=0,02592116933 \mathrm{jam}\end{array}$ \\
\hline Air tertinggal & $=0,015 \% \mathrm{x}$ air masuk \\
\hline & $\begin{array}{l}=(0,015 / 100) \times 50 \mathrm{~m}^{3} / \mathrm{jam} \\
=0.0075 \mathrm{~m}^{3} / \mathrm{jam}\end{array}$ \\
\hline Massa air out & $\begin{array}{l}=\text { massa air masuk }- \text { massa air tertinggal } \\
=50 \mathrm{~m}^{3} / \mathrm{jam}-0.0075 \mathrm{~m}^{3} / \mathrm{jam} \\
=49,9925 \mathrm{~m}^{3} / \mathrm{jam}\end{array}$ \\
\hline
\end{tabular}

Volume shell, $\mathrm{V}_{\mathrm{S}}$ :

$$
\begin{aligned}
\mathrm{H}_{\mathrm{S}} & = \\
\text { Vs } & =\frac{\pi x D^{2} x H s}{4} \\
& =\frac{3,14 x(2,55219 \mathrm{~m})^{2} x 1,274609}{4}=6,5239802 \mathrm{~m}^{3}
\end{aligned}
$$

Volume total filter :

$$
\begin{aligned}
\mathrm{V}_{\text {total }} & =\mathrm{V}_{\mathrm{s}}+\mathrm{V}_{\text {head }} \\
& =6,53239802 \mathrm{~m}^{3}+\left(2 \times 10,2258 \mathrm{~m}^{3}\right) \\
& =26,984 \mathrm{~m}^{3}
\end{aligned}
$$

f. Backwashing 
Unitek : Jurnal Universal Teknologi

Vol. 14 No.1 Januari-Juni 2021

e-ISSN : 2580-2582, p-ISSN: 2089-3957

Tabel 4. Data Hasil Perhitungan Tangki

\begin{tabular}{|c|c|c|c|c|c|c|}
\hline No & $\begin{array}{l}\text { Nama } \\
\text { Tangki }\end{array}$ & Fungsi & $\begin{array}{l}\mathrm{L} \\
(\mathrm{m})\end{array}$ & $\begin{array}{c}\mathrm{T} \\
(\mathrm{m})\end{array}$ & $\begin{array}{c}\mathrm{D} \\
(\mathrm{m})\end{array}$ & $\begin{array}{c}\mathrm{t} \\
\text { penuh } \\
(\mathrm{min})\end{array}$ \\
\hline \multirow[t]{2}{*}{1} & Lamela tank & $\begin{array}{lll}\text { adalah } & \text { tempat } & \text { tangki5,6 }\end{array}$ & 4,5 & 3,5 & - & 60 \\
\hline & & $\begin{array}{l}\text { Pencampuran zat } \mathrm{FeCL}_{3} \text { dengan } \\
\text { air laut. }\end{array}$ & & & & \\
\hline 2 & $\begin{array}{l}\text { Multi Media } \\
\text { Filter }\end{array}$ & $\begin{array}{l}\text { Menyaring air dengan- } \\
\text { menggunakan media pasir silika, } \\
\text { pasir mangan dan karbon. }\end{array}$ & - & 2,7 & 2,55 & 60 \\
\hline 3. & $\begin{array}{l}\text { Duali } \\
\text { Media Filter }\end{array}$ & $\begin{array}{l}\text { Menyaring air dengan- } \\
\text { menggunakan media pasir silika, } \\
\text { pasir mangan. }\end{array}$ & - & 2,7 & 3,7 & 60 \\
\hline \multirow[t]{2}{*}{4.} & $\begin{array}{l}\text { reservoir } \\
\text { Backwash }\end{array}$ & $\begin{array}{lcc}\text { untuk } & \text { menyimpan } & \text { air jika8,98 } \\
\text { tekanan } & \text { selama } & \text { proses }\end{array}$ & 2,24 & 3,5 & & 60 \\
\hline & & $\begin{array}{l}\text { pengolahan.Tekanan } \mathrm{MMF} \quad \mathrm{xx} \\
\text { Bar<1 bar. }\end{array}$ & & & & \\
\hline 5. & $\begin{array}{l}\text { Tank Ultra } \\
\text { Filtration }\end{array}$ & $\begin{array}{l}\text { untuk Menyimpan } \\
\text { pengolahan air - } \\
\text { Membrane Ultra Filtration. }\end{array}$ & - & 7,8 & 1,7 & 27 \\
\hline 6. & Tank SWRO & $\begin{array}{l}\text { Merupakan tangki penampungan - } \\
\text { air yang sudah diolah mesin } \\
\text { SWRO jika tekanan nya kurang } \\
\text { Jika pengolahan air lebih Totaly } \\
\text { Dissolve Solid Jumlah Zat Padat } \\
\text { Terlarut kurang dari } 400 \text { ppm } \\
\text { atau tekanan air masuk } \\
\text { klebihdari } 60 \text { bar. }\end{array}$ & - & 4,5 & 1,7 & 13 \\
\hline 7. & Tank BWRO & $\begin{array}{l}\text { Jika pengolahan air Total - } \\
\text { Dissolve Solid Jumlah Zat Padat } \\
\text { Terlarut lebih dari } 400 \text { ppm atau } \\
\text { tekan air masuk lebih dari } 60 \\
\text { bar. Maka proses pengolahan } \\
\text { akan dilanjutkan ke pencucian } \\
\text { atau pembuangan air ke proses } \\
\text { washing. }\end{array}$ & - & 4,5 & 1,7 & 13 \\
\hline 8. & $\begin{array}{l}\text { Tank } \\
\text { Cleaning }\end{array}$ & $\begin{array}{l}\text { untuk Menyimpan Air tawar - } \\
\text { untuk keperluan perawatan }\end{array}$ & - & 2,73 & 1,7 & 10 \\
\hline 9. & $\begin{array}{l}\text { Mix bed } \\
\text { Tank }\end{array}$ & $\begin{array}{l}\text { Mixed bad procerss adalah - } \\
\text { proses pemurnian air untuk } \\
\text { proses pemolesan air untuk } \\
\text { mencapai kualitas air yang } \\
\text { terdemineralisasi setelah proses } \\
\text { reverse osmosis sudah dilakukan }\end{array}$ & - & 1,38 & 1,61 & 60 \\
\hline 10 & Tank 05 & $\begin{array}{l}\text { tangki yang digunakan untuk - } \\
\text { menampung air yang akan } \\
\text { digunakan untuk kebutuhan } \\
\text { pabrik PT. Pacific Indopalm } \\
\text { Industries, Dumai. Tangki ini } \\
\text { juga merupakan hasil air baku } \\
\text { pengolhan air laut yang diolah } \\
\text { dari air asin hingga menjadi air } \\
\text { tawar yang berkualitas }\end{array}$ & - & 21 & 1,22 & 1.860 \\
\hline
\end{tabular}




\section{Simpulan}

Berdasarkan hasil analisis dan pembahasan data dapat disimpulkan bahwa pada proses SWRO pengolahan air asin menjadi air tawar dan perubahan TDS (Totaly Dissolve Solid) adalah $36.000 \mathrm{ppm}$ menjadi $400 \mathrm{ppm}$. BWRO procses, adalah proses bengolahan air payau menjadi air tawar Dan perubahan TDS (Totaly Dissolve Solid) adalah $4000 \mathrm{ppm}$ menjadi $12 \mathrm{ppm}$. Mix bed process.adalah alat untuk menghilangkan ion-ion dengan sistem kation dan anion dan menghasilkan TDS nya dari $12 \mathrm{ppm}$ menjadi $0,5 \mathrm{ppm}$. Dari hasil Perhitungan diperoleh hasil analisa dapat digunakan untuk pabrik. Karena dalam proses ini kebutuhan yang di pakai rata-rata adalah 571,81 ton/hari, sedangkan air hasil dari pengolahan adalah $40 \mathrm{~m}^{3 / j a m}$ atau setara dengan $960 \mathrm{~m}^{3} /$ hari dan pasokan tangki tersedia sebanyak 1.000 ton

\section{DAFTAR PUSTAKA}

Akhsan, masyari 2011, Analisis Perencanaan Instalasi Pengolahan Air Minum Konvesional Kota Dumai: Tugas akhir Prodi Teknik Sipil, STT Dumai, Dumai Arieyanto, Ragyl 2014. Analisa Permintaan Air Minum Isi Ulang Reverse Osmosis Di Kota Medan : Skripsi Fakultas Ekonomi Universitas Sumatera Utara, Medan

Ihsanudin, Muhammad 2017, Prarancangan Pabrik Kalsium Klorida Dari Kalsium Karbonat Dan Asam Klorida Kapasitas 20.000 Ton/Tahun: Tugas Akhir Program Studi Teknik Kimia Fakultas Teknik, Universitas Muhammadiyah Surakarta, Sukoharjo

Nurtendron, Alief 2018, Prarancangan Pabrik Monoetilen Glikol Dari Etilen Oksida Melalui Proses Hidrasi Katalitik Dengan Kapasitas 250.000 Ton/Tahun dengan sistem Tugas Khusus: Perancangan Reaktor (RE-201): Tugas Akhir Jurusan Teknik Kimia, Fakultas Teknik, Universitas Lampung, Bandar Lampung

Rezagama, arya 2009, jaringan pemipaan air minum konsep teori aplikasi

Wiranata, Agung 2014, Desain Peralatan Konversi Biomassa Menjadi Bahan Bakar Biogas Menggunakan Reaktor Tipe Partition Dengan Green Phoskko ${ }^{\circledR}$ (Gp-7) Sebagai Media Biokonversi: Tugas Akhir Jurusan Teknik Kimia Program Studi S1 (Terapan) Teknik Energi Politeknik Negeri Sriwijaya, Palembang 